Article

\title{
Ionic Liquid Hydrogel Composite Membranes (IL-HCMs)
}

\author{
Shabnam Majidi Salehi ${ }^{1,2}$, Rosangela Santagada ${ }^{1}$, Stefania Depietra ${ }^{1}$, Enrica Fontananova ${ }^{1}$, \\ Efrem Curcio $^{2}$ aD and Gianluca Di Profio ${ }^{1, * \mathbb{D}}$ \\ 1 National Research Council of Italy (CNR), Institute on Membrane Technology (ITM), Via P. Bucci c/o \\ Università della Calabria Cubo 17/C, 87036 Rende (CS), Italy; sh.majidi.s@gmail.com (S.M.S.); \\ rosangela902@virgilio.it (R.S.); stefydep92@hotmail.it (S.D.); e.fontananova@itm.cnr.it (E.F.) \\ 2 University of Calabria (UNICAL), Department of Environmental and Chemical Engineering (DIATIC), \\ Via P. Bucci Cubo 45/C, 87036 Rende (CS), Italy; e.curcio@unical.it \\ * Correspondence: g.diprofio@itm.cnr.it; Tel.: +39 0984 492010; Fax: +39-0984-402103
}

Received: 19 February 2019; Accepted: 26 April 2019; Published: 5 May 2019

check for updates

\begin{abstract}
In this work, novel hydrogel composites membranes comprising [2-(Methacryloyloxy)ethyl] dimethyl-(3-sulfopropyl)ammonium hydroxide as monomer, $\mathrm{N}, \mathrm{N}$-methylene bisacrylamide as cross-linker, and 1-butyl-3-methylimidazolium hexafluorophosphate as ionic liquid additive, have been developed. Ionic liquid hydrogel composite membranes (IL-HCMs) were tested for membrane contactors applications, aiming to reduce surface hydrophobicity of the polypropylene support, to reduce wetting tendency due to interaction with hydrophobic foulants, while affecting salts rejection in desalination operation, because of the entrapment of ILs inside the porous mesh-like structure of the gel layer. Transmembrane flux comparable to the sole polypropylene support was observed for IL content $>1 \mathrm{wt} . \%$. Furthermore, all IL membranes presented a larger rejection to sodium chloride than the PP support or the composites without ionic liquid inside. Although the overall transmembrane flux of IL-HCMs developed in this work is comparable with that of state of the art MD membranes, this study demonstrated that the strong hydrophilic hydrogel layer, with C.A. $<50^{\circ}$ for IL content larger than $1 \mathrm{wt} . \%$, serves as a stabilization coating, by providing the new media between the feed and the hydrophobic membrane surface, thus potentially controlling the diffusion of hydrophobic foulant molecules. This would result in a decrease in the membrane wetting and fouling aptitude.
\end{abstract}

Keywords: advanced separations; desalination; hydrogel composite membranes; ionic liquids membranes; membrane distillation

\section{Introduction}

Hydrogels are soft materials consisting of a mesh-like structure with polymer chains physically or chemically cross-linked and water molecules filling the interstitial spaces [1,2]. Due to their permeable net-like consistence, hydrogels can exert separation functions based on molecular size exclusion [3]. Since the mesh size can be modulated by adapting the swelling state in response to externally applied stimuli, like temperature, $\mathrm{pH}$, ionic strength, interaction with specific molecules, electric or magnetic field, transport of specific solution components through hydrogels can be controlled by a stimuli-responsive behavior [4-14].

Because of their unique features as separative media, hydrogels are facing notable implications in the field of membrane processes [15]. The combination of a hydrogel layer with a porous support provides favorable synergisms, resulting in composite materials with totally new separation functions with respect to the bulk hydrogel or the substrate, while affording improved mechanical stability of the supported soft gel phase. 
Recently, we have developed several hydrogel composite membranes, containing a hydrophobic support and a hydrophilic surface layer, whose main application is in the field of membrane contactors. Hydrogel composite membranes (HCMs) have been developed: (1) for membrane distillation (MD) [16], with enhanced salt rejection under Donnan exclusion effect generated by the polyelectrolyte nature of the gel phase, (2) as protein crystallization environment $[17,18]$, to produce crystals at lower supersaturation and of larger size compared to conventional crystallization methods, (3) as biomimetic mineralization platform [19], for the synthesis of calcium carbonate structures displaying multi-scale and hierarchical architecture, and (4) as antibacterial food package materials [20], due to the effect of enzyme crystals included in the hydrogel layer.

In this study, ionic liquid hydrogel composite membranes (IL-HCMs) have been prepared by layering a [2-(Methacryloyloxy)ethyl]dimethyl-(3-sulfopropyl)ammonium hydroxide hydrogel, cross-linked with $\mathrm{N}, \mathrm{N}$-methylene bisacrylamide in the presence of 1-butyl-3-methylimidazolium hexafluorophosphate as ionic liquid (IL) additive, and tested for MD applications. The main purpose of this work was the development of a suitable membrane functionalization strategy, that would be effective in reducing the hydrophobic interaction of the polymeric surface with potential foulants, thanks to the presence of the more hydrophilic hydrogel layer, while enforcing salts rejection due to the contribution of the ILs entrapped in the porous structure of the gel layer.

In fact, membrane fouling is particularly concerning when intrinsically hydrophobic membrane materials are used to treat feed solutions containing an abundance of organic components, due to their strong hydrophobic interactions with the polymeric surface [21-23]. This is particularly detrimental in MD applications, where severe fouling of the hydrophobic membrane is the starting point of pore wetting. In such cases, extensive feed pre-treatment is requested to remove the hydrophobic contaminants ahead the membrane process, with significant increases of treatment costs. Therefore, membrane surface modification is the most common method to improve membrane anti-fouling and anti-wetting properties in MD. For instance, shifting membrane surface hydrophobicity toward super hydrophobicity allows to generate an air gap between the liquid and the surface that helps to increase the admissible pore size prior to pore wetting occurrence, thus ensuring higher mass flux and membrane stability [24,25]. On the other hand, changing the membrane surface from hydrophobic to more hydrophilic behavior, imparts robust resistance to fouling [26-28], thanks to the formation of a hydration shell which renders the membrane surface less susceptible to interaction with the hydrophobic contaminants [29-32]. Such kind of membrane functionalization strategy is potentially suitable for membrane contactors applications, such as membrane distillation and membrane crystallization, since the hydrophilic layer protects membrane's surface from low-surface-tension components, thus preventing feed solutions from penetrating into the pores [33,34].

While the development of membranes with (super) hydrophilic skin layer has allowed the applications of MD to desalinate more challenging feed waters [22,35], little studies have been proposed so far on the development of hydrogel-functionalized membranes for membrane contactors. In a previous study, a thin layer of agarose hydrogel was positioned on the surface of a Teflon membrane, providing good anti-wetting behavior in the presence of surfactant in MD desalination [36]. In another study [37], composite membranes including poly(diallyldimethylammonium chloride)/poly acrylic acid semi-interpenetrating hydrogel on a polyvinylidene fluoride support, showed long-term robustness with $3 \mathrm{wt} . \% \mathrm{NaCl}$ solution containing cationic, ionic and non-ionic surfactants in direct contact MD experiments. Here, we show that, in addition to potentially improved membrane resistance to wetting due to the protective hydrophilic hydrogel layer, larger rejection to sodium chloride than the PP membrane can be generated under the effect of ionic liquid entrapped in the polyelectrolyte layer, with the resulting increase in charge density in the gel network that rejects ions at the solution/hydrogel interface by the Donnan exclusion potential. 


\section{Experimental Section}

\subsection{Materials}

Polypropylene (PP) flat membranes (Accurel PP 2E HF, nominal pore size $0.2 \mu \mathrm{m}$ ) were purchased from Membrana GmbH (Germany). [2-(Methacryloyloxy)ethyl]dimethyl-(3-sulfopropyl)ammonium hydroxide (monomer, SPE, cod. 537284), N,N-methylene bisacrylamide (cross-linker, MBA, cod. 146062), 2-hydroxy-2-methyl propiophenone (photoinitiator, cod. 1001451059), and 1-Butyl-3-methylimidazolium hexafluoro phosphate (ionic liquid, IL, cod. 18122) (Figure 1) were from Sigma-Aldrich (Italy). Sodium chloride ( $\mathrm{NaCl}$, cod. 131659.1211) was from Panreac (Italy). Methanol $\left(\mathrm{CH}_{3} \mathrm{OH}, \mathrm{HPLC}\right.$ grade, cod. 20844.320) was from VWR (Italy). All chemicals were used without any further purification. Milli-Q water was used for all solutions and as condensing fluid in MD tests.
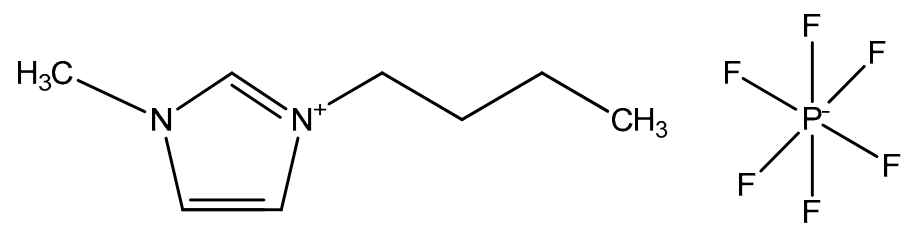

1-Butyl-3-methylimidazolium hexafluorophosphate (IL)<smiles>C=C(C)C(=O)OCC[N+](C)(C)CCCS(=O)(=O)[O-]</smiles>

[2-(Methacryloyloxy)ethyl]dimethyl-(3-sulfopropyl) ammonium hydroxide (SPE)<smiles>C=CC(=O)NCNC(=O)C=C</smiles>

N,N'-Methylenebisacrylamide (MBA)

Figure 1. Structural formula of hydrogel components used in this work.

\subsection{Preparation of Hydrogel Composite Membranes}

Polypropylene membranes, used as support for hydrogel composites, were conditioned by soaking in methanol for $24 \mathrm{~h}$ at room temperature and then dried with tissue paper immediately before use. The monomer SPE was dissolved in water by magnetic stirring $(50 \mathrm{rpm})$ at $50^{\circ} \mathrm{C}$. The cross-linker MBA was then added to the monomer solution under stirring until complete dissolution. Subsequently, the photoinitiator was added to the solution together with the proper amount of IL additives (see Table 1). The solutions were then left to stir for $1 \mathrm{~h}$ at room temperature. The pre-polymer solutions were then cast onto the conditioned PP substrate by a micrometric film applicator (Elcometer 3570) at a selected thickness of the liquid film $(100,350$, or $600 \mu \mathrm{m})$. Photo-initiated graft polymerization was then performed under the UV/Vis irradiation lamp (GR.E, $500 \mathrm{~W}$ ) in a vented exposition chamber (Helios Italquartz, Italy), for $20 \mathrm{~min}$. Composite membranes without IL were also prepared as reference samples. After that, composite membranes were washed and stored in water at room temperature for characterization and MD tests. 
Table 1. Hydrogel composite membrane sample codes, compositions of the pre-polymerization solution and thickness of the casted film layer.

\begin{tabular}{ccccccc}
\hline $\begin{array}{c}\text { Membrane } \\
\text { Sample Code }\end{array}$ & $\begin{array}{c}\text { Monomer } \\
\text { (wt.\%) }\end{array}$ & $\begin{array}{c}\text { Crosslinker } \\
\mathbf{( w t . \% )}\end{array}$ & $\begin{array}{c}\text { Photoinitiator } \\
\text { (wt.\%) }\end{array}$ & $\begin{array}{c}\mathbf{H}_{\mathbf{2}} \mathbf{O} \\
\mathbf{( w t . \% )}\end{array}$ & $\begin{array}{c}\text { IL } \\
(\mathbf{w t .} \%)\end{array}$ & $\begin{array}{c}\text { Casting } \\
\text { Thickness }(\boldsymbol{\mu} \mathbf{m})\end{array}$ \\
\hline SPE-100 & 10.0 & 1.0 & 0.3 & 88.7 & 0 & 100 \\
SPE-IL1\%-100 & 10.0 & 1.0 & 0.3 & 88.6 & 0.1 & 100 \\
SPE-IL5\%-100 & 10.0 & 1.0 & 0.3 & 88.2 & 0.5 & 100 \\
SPE-IL10\%-100 & 10.0 & 1.0 & 0.3 & 87.7 & 1.0 & 100 \\
SPE-IL15\%-100 & 10.0 & 1.0 & 0.3 & 87.2 & 1.5 & 100 \\
SPE-350 & 10.0 & 1.0 & 0.3 & 88.7 & 0 & 350 \\
SPE-IL1\%-350 & 10.0 & 1.0 & 0.3 & 88.7 & 0.1 & 350 \\
SPE-IL5\%-350 & 10.0 & 1.0 & 0.3 & 88.6 & 0.5 & 350 \\
SPE-IL10\%-350 & 10.0 & 1.0 & 0.3 & 88.2 & 1.0 & 350 \\
SPE-IL15\%-350 & 10.0 & 1.0 & 0.3 & 87.7 & 1.5 & 350 \\
SPE-600 & 10.0 & 1.0 & 0.3 & 88.7 & 0 & 600 \\
SPE-IL1\%-600 & 10.0 & 1.0 & 0.3 & 88.7 & 0.1 & 600 \\
SPE-IL5\%-600 & 10.0 & 1.0 & 0.3 & 88.6 & 0.5 & 600 \\
SPE-IL10\%-600 & 10.0 & 1.0 & 0.3 & 88.2 & 1.0 & 600 \\
SPE-IL15\%-600 & 10.0 & 1.0 & 0.3 & 87.7 & 1.5 & 600 \\
\hline
\end{tabular}

\subsection{Membrane Morphology Examination}

Morphological analyses of membranes top and cross section were performed by a Quanta $200 \mathrm{~F}$ FEI Philips scanning electron microscope (SEM). Samples were attached with carbon conductive tape to steal stubs and sputtered with chromium. The accelerating voltage was $12.0-15.0 \mathrm{kV}$ under high vacuum. Samples were cryo-fractured with liquid nitrogen prior to examine membrane cross-section.

\subsection{Water Contact Angle}

Static contact angle was measured by a goniometer (Nordtest, Italy) at ambient temperature. A $5 \mu \mathrm{L}$ drop of water was put onto the membrane sample by a micro-syringe and measurements were carried out by setting the tangents on both visible edges of the droplet. The average value of five measurements at different detection positions for each sample is reported in Table 2.

\subsection{Chemical Surface Analysis}

Surface chemical analysis of HCMs was carried out by Fourier transform infrared spectroscopy (Nicolet iS10 FT-IR spectrometer, Thermo Scientific, USA). Spectra were recorded in the range of $650-4000 \mathrm{~cm}^{-1}$ using an ATR (attenuated total reflectance) device, with a resolution of $1 \mathrm{~cm}^{-1}$, and averaged over 30 scans.

\subsection{Direct Contact Membrane Distillation Experiments}

Figure 2 shows the direct contact membrane distillation (DCMD) equipment used in this work. Technical details are reported elsewhere [16]. The starting feed and condensing water volumes were $3 \mathrm{~L}$ each. The temperature of the feed and the distillate was $60^{\circ} \mathrm{C}$ and $20^{\circ} \mathrm{C}$, respectively. Co-current solutions circulation flow rate was $12 \mathrm{~L} \cdot \mathrm{h}^{-1}$. Active membrane was $3.5 \times 10^{-3} \mathrm{~m}^{2}$. Tests were performed with pure water or $\mathrm{NaCl}$ solution $\left(1 \mathrm{~g} \cdot \mathrm{L}^{-1}\right)$ as feed. Each test lasted $6 \mathrm{~h}$. 


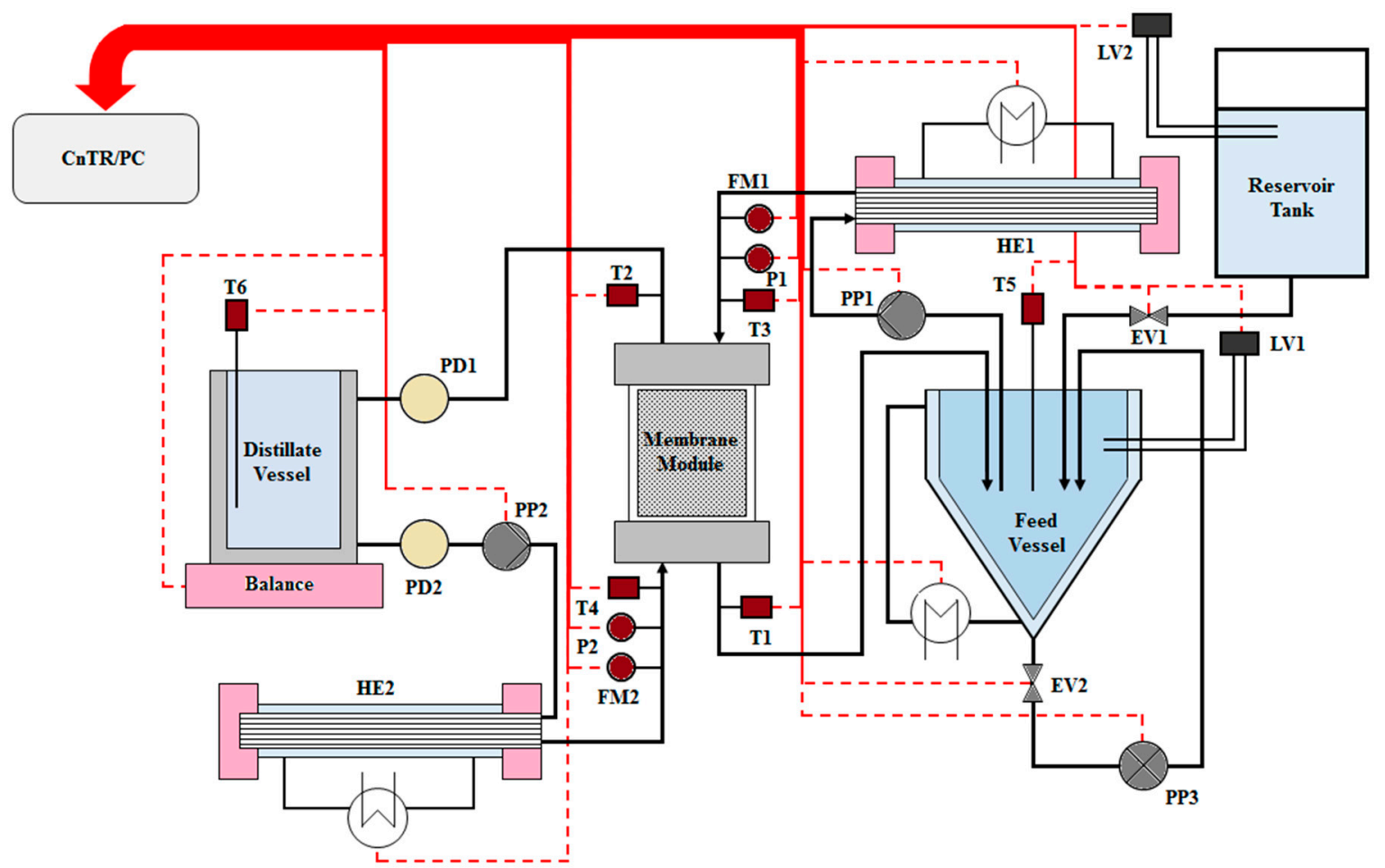

Figure 2. Membrane distillation plant used in direct contact configuration.

$\mathrm{NaCl}$ rejection was calculated by using Equation (1) by measuring the electrical conductivity (Jenway, Bibby Scientific, UK) of the distillate. Salt rejection $R$ is defined as:

$$
R=\left(1-\frac{C_{\text {distillate }}}{C_{\text {feed }}}\right) \times 100
$$

where $C_{\text {feed }}$ and $C_{\text {distillate }}$ are $\mathrm{NaCl}$ concentrations in the feed and in the distillate, respectively. $R$ is quantified by mass balance after properly considering the electrical conductivity of the overall distillate with the time and the transmembrane flux under opportune calibration. Transmembrane flux $J$ was taken as the average value detected under steady conditions (normally occurring during the last three hours of the test) and it is calculated as:

$$
J=\frac{M}{\Delta t \cdot A}
$$

with $M$ the mass of liquid passed through the membrane in the time interval $\Delta t$, and $A$ the effective membrane area.

\section{Results and Discussion}

Figure 3 shows an SEM cross-section image of an SPE-MBA ionic liquid hydrogel composite membrane (IL $10 \mathrm{wt} . \%$ ) prepared by casting the pre-polymerization solution at $100-\mu \mathrm{m}$ thickness. It is evident the homogeneous hydrogel layer, typically around $20 \pm 5 \mu \mathrm{m}$ thick, was well linked to the PP support. For the same pre-polymerization solution composition, changing the casing thickness of solution layer $(100,350$, or $600 \mu \mathrm{m})$ resulted in different width of the final hydrogel layer upon polymerization under UV irradiation. Normally, 350 and $600 \mu \mathrm{m}$-thick liquid layers load on the support lead to hydrogel layers of $80 \pm 20 \mu \mathrm{m}$ and $150 \pm 30 \mu \mathrm{m}$, respectively, after polymerization. No significant effect of the amount of IL on the final hydrogel layer thickness was observed during membrane preparation (variation less than $10 \%$ ). In the case of IL $>10 \mathrm{wt} . \%$, pre-polymerization solution presented some persistent phase separation upon mixing of the components. 


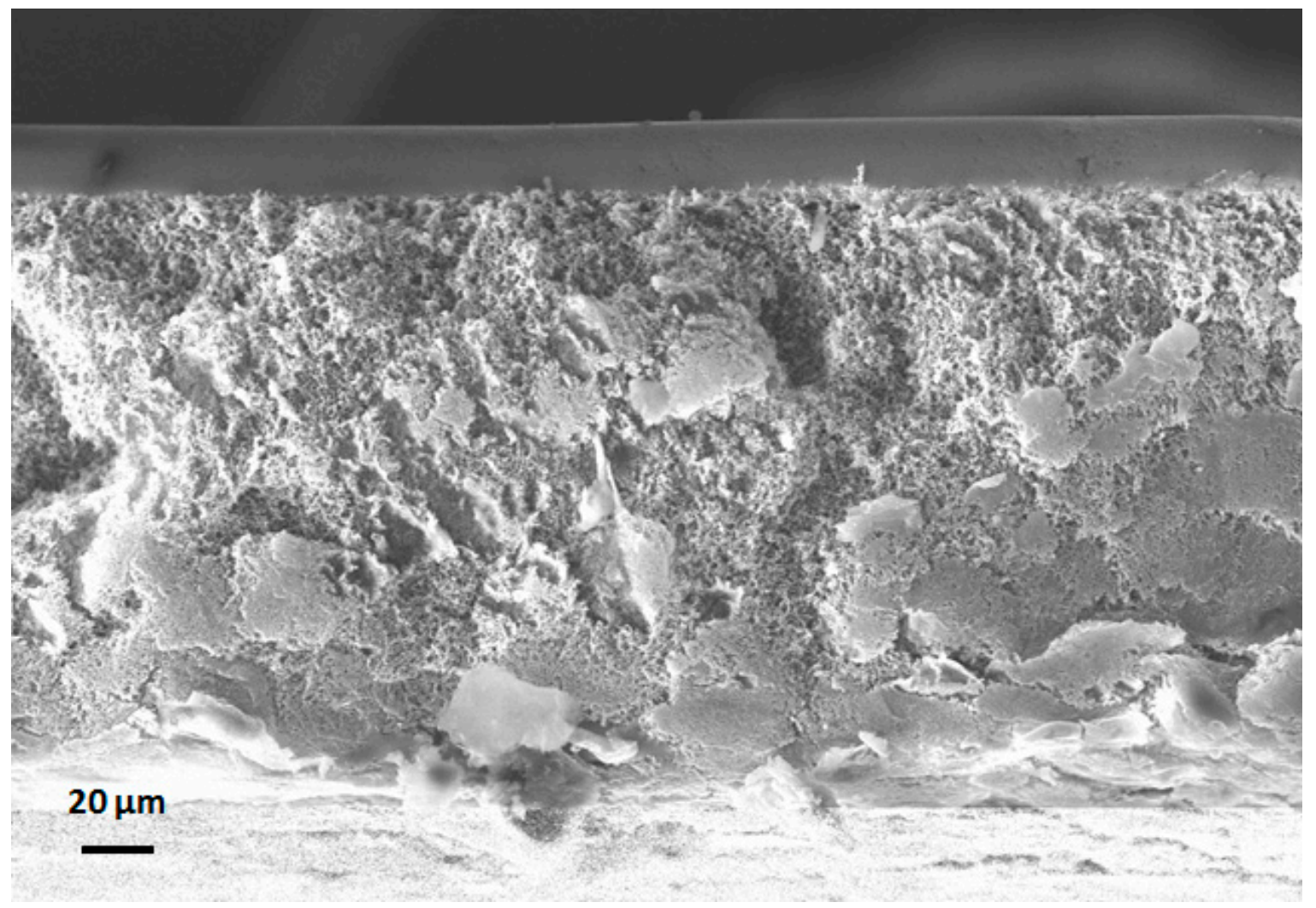

Figure 3. Typical scanning electron microscope (SEM) cross-section image of an SPE-MBA ionic liquid (IL $10 \mathrm{wt} . \%$ ) hydrogel composite membrane (HCM) prepared by casting the pre-polymerization solution at $100-\mu \mathrm{m}$ thickness.

Figure 4 displays ATR-FTIR spectra of IL-HCMs prepared with an increasing amount of IL. The growth of the peak around $840 \mathrm{~cm}^{-1}$, assigned to the asymmetric stretching of the PF6 ion and bending of the imidazolium ring [38,39], with rising amounts of IL in the pre-polymerization solution can be observed. The strong electrostatic interactions between IL and SPE components provide stability of the hydrogel phase against the possible release of the IL from the composite membrane. The cationic part of the imidazolium group of the IL (Figure 1) interacts well with the sulfonic group of the SPE, while the ammonium part of SPE has an affinity for the hexafluorophosphate ion, thus keeping electroneutrality of the system. 


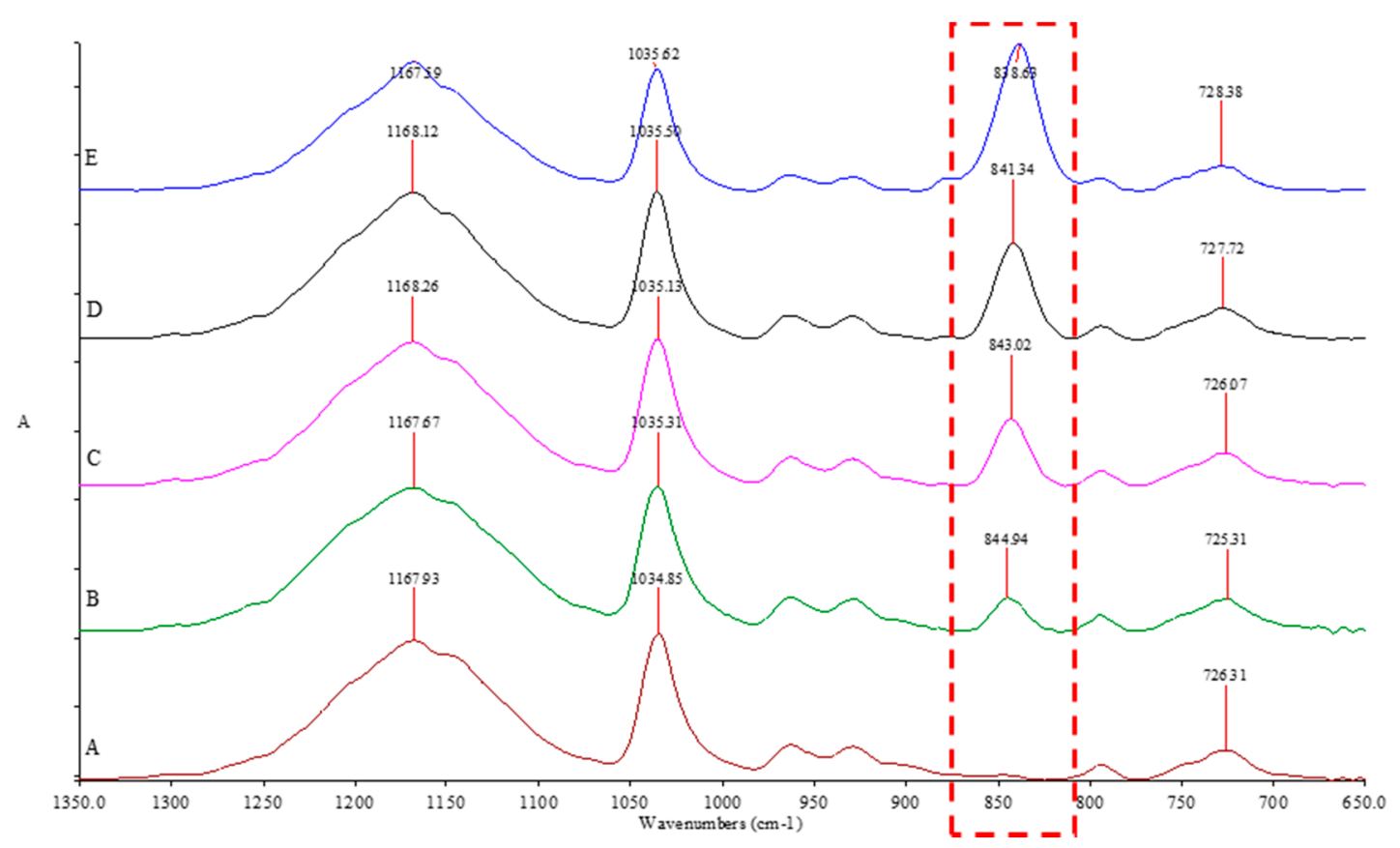

(a)

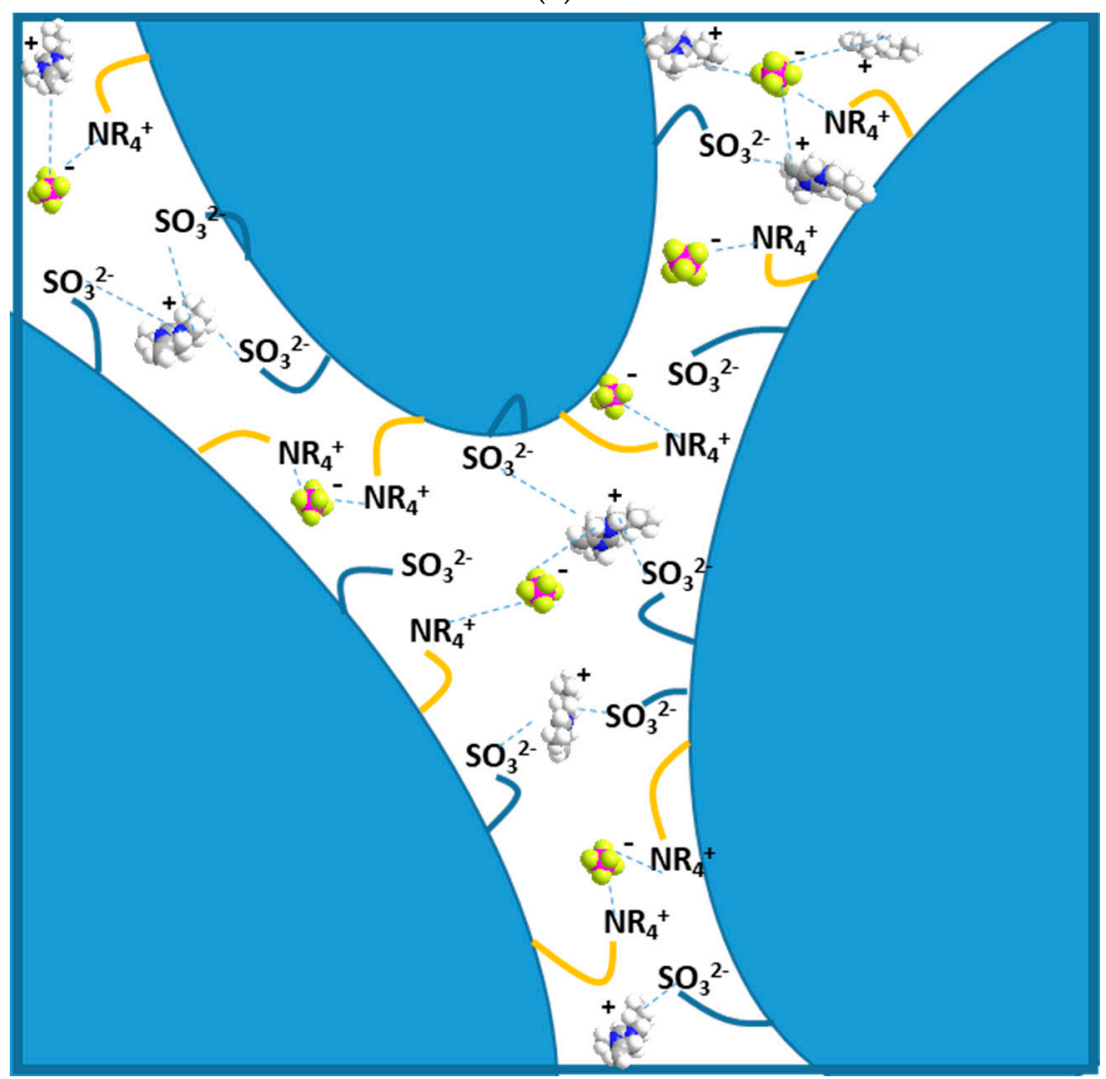

(b)

Figure 4. (a) ATR-FTIR spectra of ionic liquid hydrogel composite membranes (IL-HCMs) prepared with an increasing amount of IL (see Table 1): (A) SPE, (B) SPE-IL1\%, (C) SPE-IL5\%, (D) SPE-IL10\%, (E) SPE-IL15\%. (b) Schematic illustrating the effect of interaction between the fixed polyelectrolyte charges and mobile ionic liquid charges. White region denotes the hydrogel mesh structure with polymer chains and cross-linking points, blue spaces represent voids. The polymer mesh structure drawn here does not necessarily represent the effective system. The size of the ions relative to the mesh size is not drawn to scale. 
Table 2 reports the water contact angles for IL-HCMs prepared at 350- $\mu \mathrm{m}$ thickness of the casting solution. As observed, the strong hydrophobic nature of the polypropylene support $\left(138^{\circ}\right)$ turns into hydrophilic (C.A. $\sim 68^{\circ}$ ) with the functional hydrogel layered on the PP surface, while it becomes even more hydrophilic (C.A. $<50^{\circ}$ ) when introducing IL $>1 \mathrm{wt} . \%$ in the hydrogel layer.

Table 2. Water contact angles for IL-HCMs prepared at 350- $\mu \mathrm{m}$ film solution with different amounts of IL.

\begin{tabular}{cc}
\hline Membrane Sample Code & Water Contact Angle $\left(^{\circ}\right)$ \\
\hline PP support & $138.0 \pm 1.0$ \\
SPE-350 & $67.9 \pm 3.4$ \\
SPE-IL1\%-350 & $61.1 \pm 0.9$ \\
SPE-IL5\%-350 & $45.6 \pm 1.9$ \\
SPE-IL10\%-350 & $44.5 \pm 2.0$ \\
SPE-IL15\%-350 & $40.8 \pm 1.0$ \\
\hline
\end{tabular}

Composite membranes were tested for membrane distillation application by using the experimental equipment of Figure 2 with pure water or $\mathrm{NaCl}$ solution at $1 \mathrm{~g} \cdot \mathrm{L}^{-1}$ as feed. Figure 5 displays observed transmembrane fluxes $J$ and salt rejections $R$ performances. Despite the change of the nature of the membrane layer facing the feed from strongly hydrophobic to hydrophilic, all composite membranes demonstrated salt rejection $>99 \%$ over 6 h operation, indicating no occurrence of wetting, thus making them suitable for MD applications.

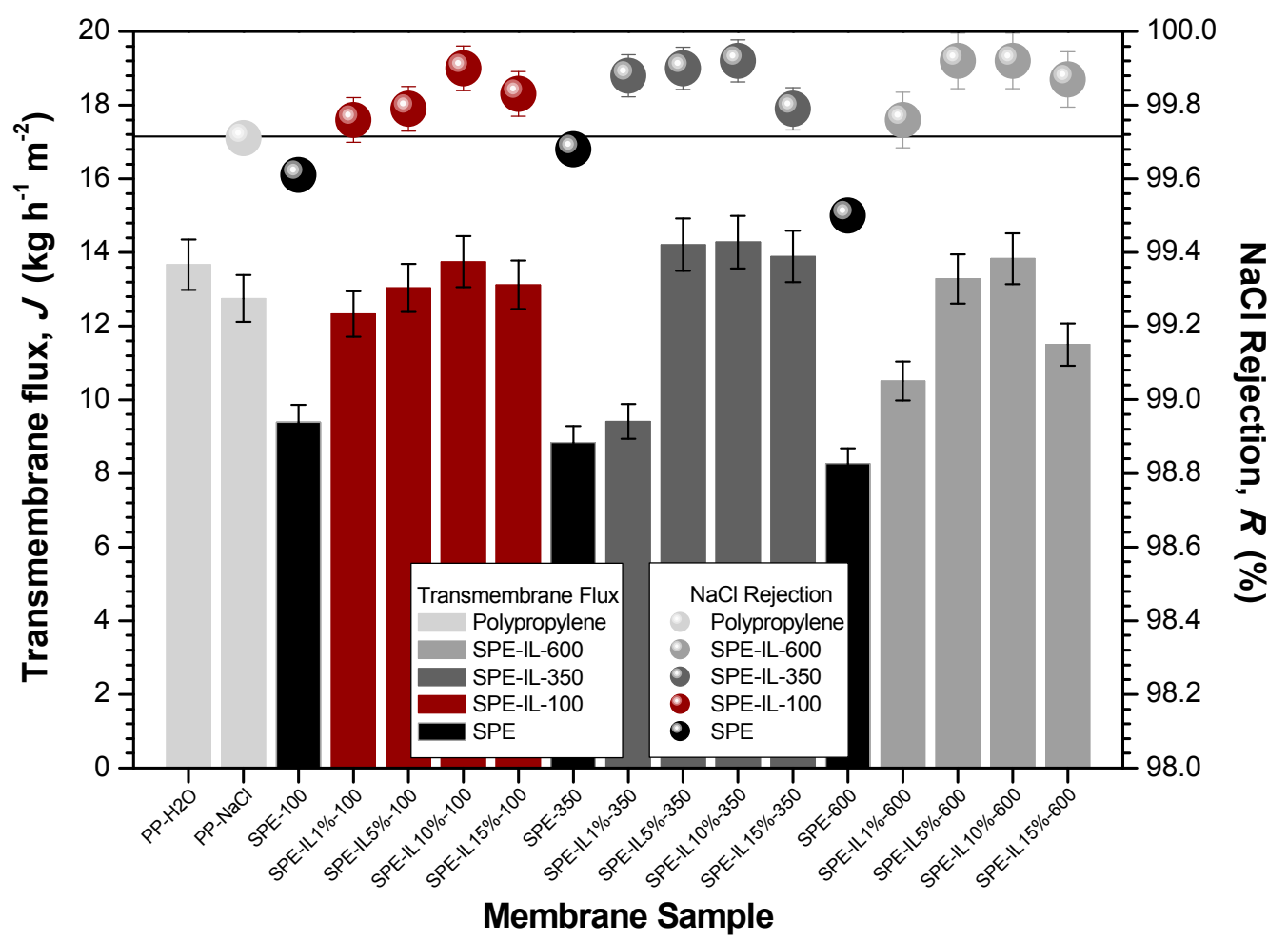

Figure 5. Observed transmembrane fluxes $J$ and $\mathrm{NaCl}$ rejections $R$ for tested membranes. Horizontal line is a guide for readers and refers to the rejection of $\mathrm{NaCl}$ salt of unfunctionalized PP support.

The first two bars of Figure 5 display the flux observed for the PP support alone with pure water $\left(\mathrm{PP}-\mathrm{H}_{2} \mathrm{O}\right)$ and with the saline solution $(\mathrm{PP}-\mathrm{NaCl})$ as feed, respectively. As noted, the slight decline in transmembrane flux (around to $7 \%$ ) for $\mathrm{NaCl}$ feed solution compared to pure water, is due to the reduction of water vapour pressure under the effect of the dissolved salt, that decreases the driving 
force $\Delta p$ (the vapour pressure gradient evaluated at the membrane surfaces) for mass-transfer in $\mathrm{MD}$ [40]. The observed rejection of $\mathrm{NaCl}$ for PP membrane support is $99.7 \%$.

The consistent reduction of $J$ is observed in Figure 5 for the membrane SPE-100, dropping by almost $30 \%$ (from $12.8 \mathrm{Kg} \cdot \mathrm{h}^{-1} \cdot \mathrm{m}^{-2}$ for pristine PP to $9.4 \mathrm{Kg} \cdot \mathrm{h}^{-1} \cdot \mathrm{m}^{-2}$ ), when the hydrogel phase is layered on the surface of the PP support in the resulting HCM. This can be explained by the additional resistance to mass transfer, compared to untreated PP membranes, generated by the presence of the hydrogel. In the case of HCMs prepared by casting the pre-polymerization solution at $350 \mu \mathrm{m}$ (SPE-350) and $600 \mu \mathrm{m}$ (SPE-600), $J$ was observed to scale almost linearly with the thickness of the casted solution. At $600 \mu \mathrm{m}$ thickness, the reduction in $J$ is almost $40 \%$ compared to the transmembrane flux registered for PP alone, dropping to $7.7 \mathrm{Kg} \cdot \mathrm{h}^{-1} \cdot \mathrm{m}^{-2}$.

When including IL at $1 \mathrm{wt.} \%$ in the casting solution (SPE-IL1\%-100), the transmembrane flux of the hydrogel-coated membrane is almost completely recovered (only $3 \%$ less) with respect to the PP, while it grows regularly up to $13.8 \mathrm{Kg} \cdot \mathrm{h}^{-1} \cdot \mathrm{m}^{-2}$ (i.e., larger than for the sole PP support) by increasing the amount of IL up to $10 \mathrm{wt} . \%$ (SPE-IL10\%-100). In the latter case, rejection of $\mathrm{NaCl}$ reaches $99.99 \%$.

Compared to a previous study, where transmembrane flux reduced by $71 \%$ when an agarose hydrogel layer was attached on the surface of a Teflon membrane [36], we found that including the IL additive in the hydrogel layer of HCMs allows almost complete salt rejection without affecting productivity.

The similar increasing trend of $J$ is observed for HCMs prepared at 350 and $600 \mu \mathrm{m}$ of casting solution, although the beneficial contribution of the IL to $J$ at lower content (1 wt.\%) is less effective than in the former case. Interestingly, increasing the amount of ionic liquid in the pre-polymerization solution, salt rejection increases regularly for all samples. For all the IL-HCMs, $\mathrm{NaCl}$ rejection overruns the observed value for the pristine PP support. Regardless of the gel layer thickness, the increase of ILs $>10 \mathrm{wt} . \%$ is associated with a slight decrease of both transmembrane flux and salt rejection. This behavior, in combination with the visual observation of liquid-liquid phase separation occurring in the pre-polymerization solution for the largest amount of ILs (15 wt.\%), indicates that this solution composition is unsuitable for the preparation of IL-HCMs.

The singular response of IL-HCMs in MD testing, depending on the gel layer composition, is due to the synergistic interaction of the hydrogel phase and the ionic liquid dispersed in the mesh-like structure. According to experiments, it is clear that the presence of mobile ionic species in the polyelectrolyte gel network is responsible for the increased $\mathrm{NaCl}$ rejection. Figure 5, in fact, reveals that salt rejection for composite membranes without IL is always lower than that observed for the PP support. In the case of $\mathrm{NaCl}$ as a feed solution, polarized groups existing in the gel network affect mobile ions distribution at the hydrogel/feed interface by interacting with $\mathrm{Na}^{+}$cations and $\mathrm{Cl}^{-}$anions. The overall flux of ions (both $\mathrm{Na}^{+}$and $\mathrm{Cl}^{-}$) from the bulk solution to the hydrogel phase is sustained by the diffusive transport under concentration gradient, which is also affected by the osmotic pressure generated by the attraction of water molecules by the strongly hydrophilic gel phase. In the absence of IL, the enhanced mobile charges density in the hydrogel network is responsible for the lower salt rejection. On the other hand, the increase of salt rejection observed for the membranes doped with IL can be rationalized considering the electrostatic repulsion (Donnan effect [41-43]) of either cationic or anionic species with charged moieties IL. Obviously, the mechanism of the Donnan exclusion in the case of ILs is more complex than simpler charged species, because of their unique molecular structure, polarity, and charge distribution [44]. SPE contains quaternary amminic and sulphonic groups (Figure 1) that may interact strongly with both cation and anion part of the IL. It is possible to speculate that the hydrophilic micro-channels formed by the interactions between the polyelectrolyte gel network and the IL (Figure 4) exert higher resistance to the transport of ionic species: $\mathrm{Na}^{+}$cations are rejected by the imidazolium component of the $\mathrm{IL}$ and $\mathrm{Cl}^{-}$anions are rejected by the phosphate ion. At the same time, the resistance to the water transport is reduced with respect to a hydrogel layer without IL, thanks to the well-interconnected network of hydrogen bonds formed between the two components (IL and polyelectrolyte). 


\section{Conclusions}

In this work, ionic liquid hydrogel composite membranes were successfully prepared and tested for membrane contactors applications. Namely, [2-(Methacryloyloxy)ethyl]dimethyl(3-sulfopropyl)ammonium hydroxide hydrogel, cross-linked with $\mathrm{N}, \mathrm{N}$-methylene bisacrylamide, and containing 1-butyl-3-methylimidazolium hexafluorophosphate as ionic liquid additive, have been demonstrated suitable for membrane distillation applications. Overall, water transport through IL-HCMs is not negatively affected by the presence of the hydrogel when the IL is included in the gel network. Complete recovery, and even improvement, of the transmembrane flux, compared to the sole hydrophobic support, was observed for IL content $>1 \mathrm{wt} . \%$. Furthermore, all IL membranes presented a larger rejection of sodium chloride than the PP membrane or the composite without ionic liquid inside. This is due to the effect of the ionic liquid entrapped inside the polyelectrolyte layer with the resulting increase in charge density in the gel network that rejects ions at the feed/hydrogel interface under the effect of the Donnan exclusion potential. This effect brings salt rejection as high as $99.99 \%$ for composite membranes containing IL up to $10 \mathrm{wt}$ \%. Increasing further the amount of IL induces phase separation in the pre-polymerization solution, thus making this composition unsuitable for IL-HCMs preparation.

Although the overall transmembrane flux of IL-HCMs developed in this work is comparable with that of state-of-the-art MD membranes, this study demonstrated that a hydrophobic macroporous membrane could be functionalized by a hydrogel layer comprising IL. The strong hydrophilic hydrogel, in addition to the increased transmembrane flux and salt rejection, serves as a stabilization layer, by providing the new media between the feed and the hydrophobic membrane surface, thus potentially controlling the diffusion of hydrophobic foulant molecules. This would result in a decrease in the membrane wetting and fouling aptitude.

Author Contributions: Conceptualization, G.D.P.; methodology, G.D.P., E.F., E.C.; investigation, S.M.S., R.S., and S.D.; data curation, S.M.S., R.S., and S.D.; writing-original draft preparation, G.D.P.; writing-review and editing, G.D.P., E.F., and E.C.; supervision, G.D.P., E.F.; funding acquisition, G.D.P., E.C.

Funding: The Education, Audiovisual and Culture Executive Agency (EACEA) for the financial support of the doctoral research fellowship of S. M. S. through the programme Erasmus Mundus Doctorate in Membrane Engineering-EUDIME (FPA 2011-0014).

Acknowledgments: Authors wish to thank The Education, Audiovisual and Culture Executive Agency (EACEA) for the financial support to the doctoral research fellowship of S. M. S. through the programme Erasmus Mundus Doctorate in Membrane Engineering-EUDIME (FPA 2011-0014).

Conflicts of Interest: The authors declare no conflict of interest.

\section{References}

1. Osada, Y.; Gong, J.P. Soft and Wet Materials: Polymer Gels. Adv. Mater. 1998, 10, 827. [CrossRef]

2. Peppas, N.A.; Hilt, J.Z.; Khademhosseini, A.; Langer, R. Hydrogels in Biology and Medicine: From Molecular Principles to Bionanotechnology. Adv. Mater. 2006, 18, 1345-1360. [CrossRef]

3. Tong, J.; Anderson, J.L. Partitioning and diffusion of proteins and linear polymers in polyacrylamide gels. Biophys. J. 1996, 70, 1505-1513. [CrossRef]

4. Tenhaeff, W.E.; Gleason, K.K. Surface-Tethered pH-Responsive Hydrogel Thin Films as Size-Selective Layers on Nanoporous Asymmetric Membranes. Chem. Mater. 2009, 21, 4323-4331. [CrossRef]

5. Hirokawa, Y.; Tanaka, T. Volume phase transition in a nonionic gel. J. Chem. Phys. 1984, 81, 6379-6380. [CrossRef]

6. Polotsky, A.A.; Plamper, F.A.; Borisov, O.V. Collapse-to-Swelling Transitions in pH- and Thermoresponsive Microgels in Aqueous Dispersions: The Thermodynamic Theory. Macromolecules 2013, 46, 8702-8709. [CrossRef]

7. Beebe, D.J.; Moore, J.S.; Bauer, J.M.; Yu, Q.; Liu, R.H.; Devadoss, C.; Jo, B.-H. Functional hydrogel structures for autonomous flow control inside microfluidic channels. Nature 2000, 404, 588-590. [CrossRef] 
8. Chang, C.; He, M.; Zhou, J.; Zhang, L. Swelling Behaviors of pH- and Salt-Responsive Cellulose-Based Hydrogels. Macromolecules 2011, 44, 1642-1648. [CrossRef]

9. Tanaka, T.; Nishio, I.; Sun, S.T.; Uenonishio, S. Collapse of Gels in an Electric Field. Science 1982, 218, 467-469. [CrossRef]

10. Suzuki, A.; Tanaka, T. Phase transition in polymer gels induced by visible light. Nature 1990, 346, $345-347$. [CrossRef]

11. Mosiewicz, K.A.; Kolb, L.; van der Vlies, A.J.; Martino, M.M.; Lienemann, P.S.; Hubbell, J.A.; Ehrbar, M.; Lutolf, M.P. In situ cell manipulation through enzymatic hydrogel photopatterning. Nat. Mater. 2013, 12, 1072-1078. [CrossRef]

12. Frey, W.; Meyer, D.E.; Chilkoti, A. Dynamic addressing of a surface pattern by a stimuli-responsive fusion protein. Adv. Mater. 2003, 15, 248-251. [CrossRef]

13. Mart, R.J.; Osborne, R.D.; Stevens, M.M.; Ulijn, R.V. Peptide-based stimuli-responsive biomaterials. Soft Matter 2006, 2, 822-835. [CrossRef]

14. Wilson, A.N.; Guiseppi-Elie, A. Bioresponsive Hydrogels. Adv. Healthcare Mater. 2013, 2, 520-532. [CrossRef] [PubMed]

15. Yang, Q.; Adrus, N.; Tomicki, F.; Ulbricht, M. Composites of functional polymeric hydrogels and porous membranes. J. Mater. Chem. 2011, 21, 2783-2811. [CrossRef]

16. Salehi, S.M.; Di Profio, G.; Fontananova, E.; Nicoletta, F.P.; Curcio, E.; De Filpo, G. Membrane Distillation by Novel Hydrogel Composite Membranes. J. Membr. Sci. 2016, 504, 220-229. [CrossRef]

17. Di Profio, G.; Polino, M.; Nicoletta, F.P.; Belviso, B.D.; Caliandro, R.; Fontananova, E.; De Filpo, G.; Curcio, E.; Drioli, E. Tailored hydrogel membranes for efficient protein crystallization. Adv. Funct. Mater. 2014, 24, 1582-1590. [CrossRef]

18. Salehi, S.M.; Manjua, A.C.; Belviso, B.D.; Portugal, C.A.M.; Coelhoso, I.M.; Mirabelli, V.; Fontananova, E.; Caliandro, R.; Crespo, J.G.; Curcio, E.; et al. Hydrogel Composite Membranes Incorporating Iron Oxide Nanoparticles as Topographical Designers for Controlled Heteronucleation of Proteins. Cryst. Growth Des. 2018, 18, 3317-3327. [CrossRef]

19. Di Profio, G.; Salehi, S.M.; Caliandro, R.; Guccione, P.; Nico, G.; Curcio, E.; Fontananova, E. Bioinspired synthesis of $\mathrm{CaCO}_{3}$ superstructures through a novel hydrogel composite membranes mineralization platform: A comprehensive view. Adv. Mater. 2016, 28, 610-616. [CrossRef] [PubMed]

20. Mirabelli, V.; Salehi, S.M.; Angiolillo, L.; Belviso, B.D.; Conte, A.; del Nobile, M.A.; Di Profio, G.; Caliandro, R. Enzyme Crystals and Hydrogel Composite Membranes as New Active Food Packaging Material. Glob. Chall. 2018, 2, 1700089. [CrossRef]

21. Israelachvili, J.; Pashley, R. The hydrophobic interaction is long range, decaying exponentially with distance. Nature 1982, 300, 341-342. [CrossRef]

22. Tsao, Y.; Evans, D.; Wennerstrom, H. Long-range attractive force between hydrophobic surfaces observed by atomic force microscopy. Science 1993, 262, 547-550. [CrossRef] [PubMed]

23. Meyer, E.E.; Rosenberg, K.J.; Israelachvili, J. Recent progress in understanding hydrophobic interactions. Proc. Natl. Acad. Sci. USA 2006, 103, 15739-15746. [CrossRef]

24. Lafuma, A.; Quere, D. Superhydrophobic states. Nat. Mater. 2003, 2, 457-460. [CrossRef]

25. Ma, Z.; Hong, Y.; Ma, L.; Su, M. Superhydrophobic membranes with ordered arrays of nanospiked microchannels for water desalination. Langmuir 2009, 25, 5446-5450. [CrossRef]

26. Zuo, G.; Wang, R. Novel membrane surface modification to enhance anti-oil fouling property for membrane distillation application. J. Membr. Sci. 2013, 447, 26-35. [CrossRef]

27. Wang, Z.; Elimelech, M.; Lin, S. Environmental applications of interfacial materials with special wettability. Environ. Sci. Technol. 2016, 50, 2132-3150. [CrossRef] [PubMed]

28. Wang, Z.; Jin, J.; Hou, D.; Lin, S. Tailoring surface charge and wetting property for robust oil-fouling mitigation in membrane distillation. J. Membr. Sci. 2016, 516, 113-122. [CrossRef]

29. Pashley, R.M. Hydration forces between mica surfaces in aqueous electrolyte solutions. J. Colloid Interface Sci. 1981, 80, 153-162. [CrossRef]

30. Chen, S.; Li, L.; Zhao, C.; Zheng, J. Surface hydration: Principles and applications toward low-fouling/nonfouling biomaterials. Polymer 2010, 51, 5283-5293. [CrossRef] 
31. Tiraferri, A.; Kang, Y.; Giannelis, E.P.; Elimelech, M. Superhydrophilic thin-film composite forward osmosis membranes for organic fouling control: Fouling behavior and antifouling mechanisms. Environ. Sci. Technol. 2012, 46, 11135-11144. [CrossRef] [PubMed]

32. Fe, H.; Lu, D.; Cheng, W.; Zhang, T.; Lu, X.; Liu, Q.; Jiang, J.; Technology, P.; Cheng, W.; Zhang, T.; et al. Hydrophilic $\mathrm{Fe}_{2} \mathrm{O}_{3}$ dynamic membrane mitigating fouling of support ceramic membrane in ultrafiltration of oil/water emulsion. Sep. Purif. Technol. 2016, 165, 1-9.

33. Lin, S.; Nejati, S.; Boo, C.; Hu, Y.; Osuji, C.O.; Elimelech, M. Omniphobic membrane for robust membrane distillation. Environ. Sci. Technol. Lett. 2014, 1, 443-447. [CrossRef]

34. Boo, C.; Lee, J.; Elimelech, M. Engineering surface energy and nanostructure of microporous films for expanded membrane distillation applications. Environ. Sci. Technol. 2016, 50, 8112-8119. [CrossRef]

35. Wang, Z.; Hou, D.; Lin, S. Composite membrane with underwater-oleophobic surface for anti-oil-fouling membrane distillation. Environ. Sci. Technol. 2016, 50, 3866-3874. [CrossRef] [PubMed]

36. Lin, P.J.; Yang, M.C.; Li, Y.L. Prevention of surfactant wetting with agarose hydrogel layer for direct contact membrane distillation used in dyeing wastewater treatment. J. Membr. Sci. 2015, 475, 511-520. [CrossRef]

37. Ardeshiri, F.; Akbari, A.; Peyravi, M.; Jahanshahi, M. PDADMAC/PAA semi-IPN hydrogel-coated PVDF membrane for robust anti-wetting in membrane distillation. J. Ind. Eng. Chem. 2019, 74, 14-25. [CrossRef]

38. Talaty, E.R.; Raja, S.; Storhaug, V.J.; Do1lle, A.; Carper, W.R. Raman and Infrared Spectra and ab Initio Calculations of C2-4MIM Imidazolium Hexafluorophosphate Ionic Liquids. J. Phys. Chem. B 2004, 108, 13177-13184. [CrossRef]

39. Paulechka, Y.U.; Kabo, G.J.; Blokhin, A.V.; Vydrov, O.A.; Magee, J.W.; Frenkel, M. Thermodynamic Properties of 1-Butyl-3-methylimidazolium Hexafluorophosphate in the Ideal Gas State. J. Chem. Eng. Data 2003, 48, 457-462. [CrossRef]

40. Peng, P.; Fane, A.G.; Li, X. Desalination by membrane distillation adopting a hydrophilic membrane. Desalination 2005, 173, 45-54. [CrossRef]

41. Hagmeyer, G.; Gimbel, R. Modelling the salt rejection of nanofiltration membranes for ternary ion mixtures and for single salts at different $\mathrm{pH}$ values. Desalination 1998, 117, 247-256. [CrossRef]

42. Garcia-Aleman, J.; Dickson, J.M. Permeation of mixed-salt solutions with commercial and pore-filled nanofiltration membranes: Membrane charge inversion phenomena. J. Membr. Sci. 2004, 239, 163-172. [CrossRef]

43. Schaep, J.; van der Bruggen, B.; Vandecasteele, C.; Wilms, D. Influence of ion size and charge in nanofiltration. Sep. Purif. Technol. 1998, 14, 155-162. [CrossRef]

44. Gan, Q.; Rooney, D.; Xue, M.; Thompson, G.; Zou, Y. An experimental study of gas transport and separation properties of ionic liquids supported on nanofiltration membranes. J. Membr. Sci. 2006, 280, 948-956. [CrossRef]

(C) 2019 by the authors. Licensee MDPI, Basel, Switzerland. This article is an open access article distributed under the terms and conditions of the Creative Commons Attribution (CC BY) license (http://creativecommons.org/licenses/by/4.0/). 